Ethiopian Journal of Environmental Studies \& Management 10(4): 461 - 471, 2017.

ISSN:1998-0507

doi: https://dx.doi.org/10.4314/ejesm.v10i4.4

Submitted: November 21, 2016

Accepted: May 25, 2017

\title{
DETERMINANTS OF ADOPTION OF BIOSECURITY PRINCIPLES BY POULTRY FARMERS IN KWARA STATE, NIGERIA
}

\author{
TSADO, J.H., ${ }^{1}$ FATOKI, P., ${ }^{1}$ AJIBOLA B.0., ${ }^{1}$ ABUBAKAR, A. ${ }^{1}$ AND TSADO, D.N. ${ }^{2}$ \\ ${ }^{1}$ Department of Agricultural Economics and Extension Technology \\ ${ }^{2}$ Department of Animal production Federal University of Technology Minna - Niger state, \\ Nigeria
}

\begin{abstract}
The study assessed the determinant factors influencing the adoption of biosecurity principles by poultry farmers in Kwara State, Nigeria. The major objective was to determine poultry farmer awareness and adoption of various biosecurity principles. $A$ multistage sampling technique was used to select the respondents. Data for the study were collected from 92 respondents, through the use of structured questionnaire and interview schedule. Data were subjected to both descriptive and inferential statistic (Logit regression analysis). The results revealed that majority of the poultry farmers were still within their productive and active age (M=47years), majority were well educated ( $M=15$ years) and majority (60\%) reared both broilers and layers. The study also showed that there was $100 \%$ awareness and trial of all the biosecurity principles under consideration The most adopted biosecurity principles with 100\% adoption however, were provision of adequate ventilation, removal of dead birds, offering of good quality feed and water, vaccination and provision of proper medication. The result further revealed that respondents with larger number of birds (1.994), access to credit (1.715), frequent contact with extension agents (2.183) and access to training (2.083) had high propensity to adoption of biosecurity activities. The respondents perceived all the biosecurity principles under consideration as effective in preventing looses in their farms. They however, perceived the following constraints as severe constraints: inadequate capital $(M=2.96)$, disease and parasites $(M=2.97)$ and inadequate credit facility $(M=2.74)$. The study concludes that poultry farmers' awareness of biosecurity activities was high, with moderate rate of adoption of the activities; they however, perceived biosecurity principles as effective means of preventing diseases infection.
\end{abstract}

Key Words: Adoption, biosecurity principles, poultry, farmers

\section{Introduction}

Food and Agriculture Organization of the United Nations estimated the global population of domestic chickens and ducks at over 18 billion and 1 billion, respectively (FAO, 2008). Based on the number of animals, poultry represents the largest domestic animal stock in the

*Corresponding Author: Tsado, J.H.

Email: jacobtsado2007@yahoo.com 
world. The industry is dominated by commercial farms while in developing countries, production consists of small commercial farms, village or "backyard" (traditional) poultry, which is soften extensive. Poultry industry is however, becoming increasingly important in Nigeria with a steady increase in the demand for chicken and egg products sourced from both traditional and super markets. (FAO, 2008; FAO, 2009; FAO, 2012; Susilowati et al., 2013)

Biosecurity is the implementation of measures that reduce the risk of the introduction and spread of disease agents; it requires the adoption of a set of attitudes and behaviours by farmers to reduce risk in all activities involving domestic, captive, exotic and wild birds and their products (Fasina et al., 2011; Patrick and Jubb 2010; FAO, 2008). In the opinion of Nyaga (2007), biosecurity principles include simple practices and procedures which when applied prevent entry of disease agents into a farm or the exit of the disease agent from infected premises. Biosecurity includes controlling movement of stock, persons, equipment and products into the clean farm and out of infected premises; also it involves methods that enable the farm to remain in a state of sustained cleanliness, referred to as sanitation.

Poultry closely interact with humans in the same household as well as with wild birds and other livestock where they are also exposed to vermin and predators. Poor or absent of disease control strategies and inadequate management practices result in high levels of baseline mortality due to predators (e.g. rodents, snakes, small carnivores) or infectious diseases e.g. Newcastle Disease (ND), Salmonellosis, Gumboro disease or fowl typhoid (Badubi et al., 2009). Full term poultry farmers, do not develop a positive or favourable attitude towards biosecurity principles to minimize losses that are usually caused by diseases, most of the poultry farmers do not adopt these principles, as such they usually incurred a lot of looses which directly affect their income generation from poultry husbandry.

The three major principles of biosecurity are segregation, cleaning and disinfection. Biosecurity activities ranges from simple, low cost measure such as putting locks on gates to the more costly measures such as high pressure water sprayer to clean cars and constructing shower blocks to secure visitors and workers as they enter the farm (Fasina, 2011; Henson and Jaffe, 2005). This study is important because it provide a better understanding of the present level of awareness, adoption and the economic drivers and constraints faced by poultry farmers, this is necessary if appropriate government policy and market incentives structures can be established that encourage the reduction in poultry disease prevalence, this will in no small measure reduce the colossal losses usually incur by broiler and layer farmers

\section{Objective of the Study}

The objectives of the study include to:

Describe the socio economic characteristics of the poultry farmers, determines poultry farmer awareness and adoption of the various biosecurity principles, ascertain the factors affecting the adoption of biosecurity principle and to examine the constraints faced by the poultry farmers in adopting biosecurity principles. 


\section{Study Area}

Kwara state lies approximately between Longitude $5^{\circ} 00^{\prime} \mathrm{E}$ and Latitude $8^{\circ} 30^{\prime}$ N. Its State capital is Ilorin. Kwara State has a land mass of about 36,825 $\mathrm{km} 2(14,218$ sq. mi) and population of about of 3,121,855 as estimated in 2015 (United Nation Population Fund, 2015). The climate of the state is characterized by most spectacular landforms and the seasons include both the wet and dry seasons, each lasting for about six months. The rainy season begins towards the end of March and lasts till October. The major occupation of the people is farming, trading and rearing of animals like cattle, goat and sheep.

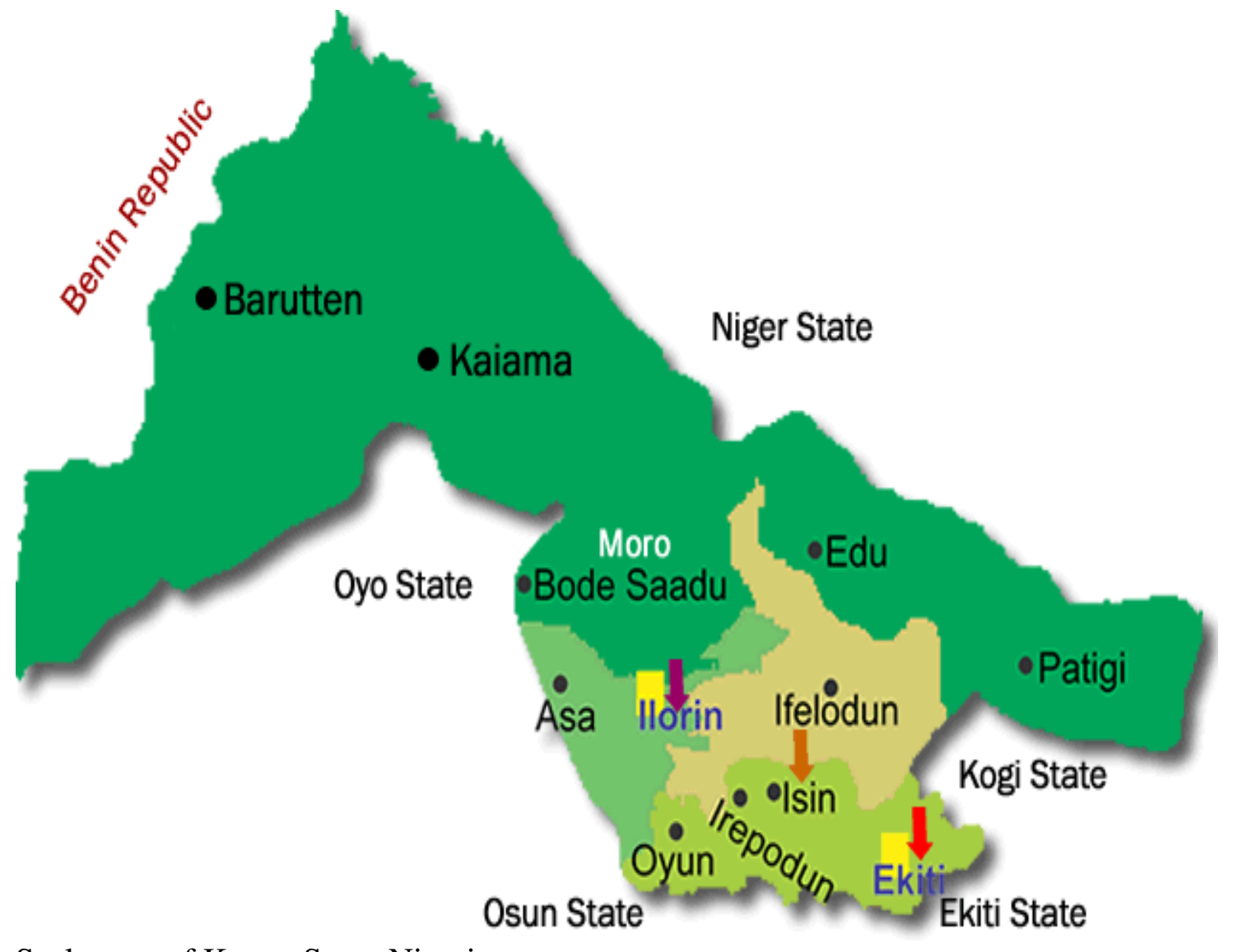

Scale map of Kwara State, Nigeria

Methodology

Sampling Technique and Sample Size

A multi-stage sampling technique was used in the selection of the respondents within the three agricultural Zones of Kwara state, namely; Kwara Central, Kwara North and Kwara South. In the first stage, two (2) Local
Government Areas were purposively selected from each agricultural Zone based on the predominance of poultry production in the Area. The selected Local Government Areas include; Ilorin West, Ilorin East, Edu, Patigi, Ifelodun and Irepodun. In the second stage, Six (6) villages were randomly selected from 
each Local Government Areas. In the third stage, from the sample frame of the six villages from each Local Government Area, forty percent $(40 \%)$ of the population were sampled. A total of thirty eight (38), twenty eight (28) and twenty six (26) respondents were sampled from Kwara central, Kwara north and Kwara south respectively, given a total sample size of Ninety two (92) respondents

\section{Data Collection and Analysis}

Primary data was used for the study. Structured questionnaire/interviews schedule was used to collect information from the respondents within the study area. Both descriptive and inferential statistics were used for data analysis, descriptive statistics that were used include: frequency distribution, mean obtained through administration of Likart type of scale. Poisson regression model was used to determine the factors affecting the adoption of bio security principles by the poultry farmers

\section{Specification of Models}

\section{Poisson Regression Model}

Poisson regression is a form of regression analysis used to model count data and contingency tables. Poison regression assumes the response variable $\mathrm{Y}$ has a Poisson distribution and assumes the logarithm of its expected value which can be modelled by a linear combination of unknown parameters. Poisson regression model is sometimes known as log- linear model, especially when used to model contingency tables. Poisson regression models are generalized linear models with the logarithm as the link function and the Poisson distribution function.

The model is expressed in implicit form as:
$\mathrm{Y}=\mathrm{f}\left(\mathrm{X}_{1}, \mathrm{X}_{2}, \mathrm{X}_{3}, \mathrm{X}_{4}, \mathrm{X}_{5}, \mathrm{X}_{6}, \mathrm{X}_{7},\right)$

The functional form is expressed in the explicit form as:

$\mathrm{Y}=\mathrm{b}_{0}+\mathrm{b}_{1} \mathrm{X}_{1}+\mathrm{b}_{2} \mathrm{X}_{2}+\mathrm{b}_{3} \mathrm{X}_{3}+\mathrm{b}_{4} \mathrm{X}_{4}+\mathrm{b}_{5} \mathrm{X}_{5}$

$+b_{6} X_{6}+b_{7} X_{7}+U$

Where:

$\mathrm{Y}=$ Biosecurity principle adopted (count variable)

$\mathrm{X}_{1}=$ Age (in years)

$\mathrm{X}_{2}=$ Education (Years spent in school)

$\mathrm{X}_{3}=$ Household size (numbers of people in the household)

$\mathrm{X}_{4}=$ Number of birds

$\mathrm{X}_{5}=$ Experience (years spent in farm)

$\mathrm{X}_{6}=$ Extension contact (number of visits)

$\mathrm{X}_{7}=$ Access to training (number of time)

In $=$ Logarithm

$\mathrm{b}_{0}=$ Constant

$\mathrm{b}_{1}-\mathrm{b}_{7}=$ Regression coefficient

$\mathrm{X}_{1}-\mathrm{X}_{7}=$ Independent variable

\section{Results and Discussion}

\section{Personal Characteristics of the Respondents}

The result of the socioeconomic characteristics of the respondents in Table 1 revealed that, the age of the respondents ranges from 20 to 50 years, with mean age of 47 years, which implies that majority of the poultry farmers in the study area were still in there active and productive age. This is consistent with findings of Musa et al. (2009) and Patrick and Jubb (2010) who find that older farmers had fewer propensities to contribute in term of labour utilization. Majority $(92.5 \%)$ of the poultry farmers were male, implying that male dominate the industry in the study area. Over $92 \%$ of the poultry farmers were married, $4.3 \%$ were single, while $2.2 \%$ and $1.1 \%$ were separated and widow/widower respectively. This is 
implies that majority of the poultry farmers in the study area have additional responsibilities of catering for their families.

On the respondents' educational level, results revealed that majority $(91.3 \%)$ had up to tertiary education, with mean of 15 years. This will directly influence their knowledge level and consequently their daily managerial operations. Also $64.1 \%$ of the respondent had household sizes of between 1-10 and $29.3 \%$ and $6.5 \%$ had household sizes of between 11-20 and 21-30, respectively. Implying that majority of them had moderate household sizes. This is in agreement with the findings of Onwubuya et al. (2009) who stated that in Tropical Africa majority of the farmers now have small to moderate households and that large households are disappearing with increasing economic and financial hardship and raising demand for social and educational obligations. On the types of birds reared by the respondents, about $60 \%$ reared both broilers and layers while only $30.4 \%$ and $9.8 \%$ specialises in rearing broilers and layers, respectively. This is consistent with findings of Susilowati (2013), who stressed that in response to increasing population and improved standard of living, the demand has been increasing for both broilers and layers. In Batwana however, Badusi et al. (2004), reported that majority of the smallholder poultry farmers specialises in broilers production

Table 1: Socio-economic characteristics of the respondents

\begin{tabular}{llll}
\hline variables & Frequency & Percentage & Mean \\
\hline Age & 6 & & \\
$<20$ & 18 & 6.5 & \\
$21-30$ & 40 & 19.6 & 47 \\
$31-40$ & 20 & 43.5 & \\
$41-50$ & 8 & 21.7 & \\
$>50$ & & 8.7 &
\end{tabular}

Sex

Female

Male

Marital status

Single

Married

Widow/widower

Separated

Educational status

No formal education

Primary education

Secondary education

Tertiary education
2.2

1.1

1.1

6.5

$84 \quad 91.3$


Household size

$\begin{array}{llll}1-10 & 59 & 61.1 & 10 \\ 11-20 & 27 & 29.3 & 10 \\ 21-30 & 6 & 6.5 & \end{array}$

Types of birds reared

$\begin{array}{lll}\text { Broilers } & 28 & 30.4\end{array}$

Layers $\quad 9 \quad 9.8$

Both $\quad 55 \quad 59.8$

Table 2: Distribution of the respondents based on their overall adoption of various biosecurity principles

\begin{tabular}{llll}
\hline & Adoption Rate & & \\
\hline Biosecurity Principles & Aware & Tried & Adopted \\
\hline Sanitation & $92(100 \%)$ & $92(100 \%)$ & $91(98.9 \%)$ \\
& & & \\
Vaccination & $92(100 \%)$ & $92(100 \%)$ & $91(98.9 \%)$ \\
Heating & $92(100 \%)$ & $92(100 \%)$ & $76(82.6 \%)$ \\
Cooling & $92(100 \%)$ & $92(100 \%)$ & $67(72.8 \%)$ \\
Ventilation & $92(100 \%)$ & $92(100 \%)$ & $92(100 \%)$ \\
Proper medication & $92(100 \%)$ & $92(100 \%)$ & $80(87.0 \%)$ \\
Isolation & $92(100 \%)$ & $91(98.9 \%)$ & $61(66.3 \%)$ \\
Traffic control & $92(100 \%)$ & $90(97.8 \%)$ & $57(62.0 \%)$ \\
Control of rodents & $92(100 \%)$ & $91(98.9 \%)$ & $69(75.0 \%)$ \\
Removal of dead birds & $92(100 \%)$ & $92(100 \%)$ & $92(100 \%)$ \\
Offering good quality feeds & $92(100 \%)$ & $92(100 \%)$ & $92(100 \%)$ \\
Offering good quality water & $92(100 \%)$ & $92(100 \%)$ & $92(100 \%)$ \\
\hline
\end{tabular}

Table 2 revealed that majority of the respondents were fully $(100 \%)$ aware and adopted the following bio-security principles: Removal of dead birds, offering good quality feeds, ventilation and offering good quality water. This is closely followed by sanitation (98.9\%) and removal of dead birds $(98.9 \%)$. This implies that majority of the respondent had good knowledge of bio-security principles and this consequently affected their rate of adoption. This is consistent with the four principles documented by Pierson (2001), these include: principle of isolation, good hygiene, flock health care and lastly principle of good management. Traffic control was however, less adopted by the poultry farmers because majority of them reared their birds under intensive care, which is in line with the findings of Nyaga (2009), who stressed that the type of biosecurity adopted by a farmer depend on his/her husbandry system. 
Table 3: Factors influencing poultry farmer's adoption of biosecurity principles

\begin{tabular}{llcl}
\hline Variable & Coefficient & Standard Error & Z-value \\
\hline Age & .00783198 & .01026208 & 0.763 \\
Education & -.00713599 & .01932248 & -0.369 \\
Experience & .01690907 & .01545296 & 1.094 \\
Household size & .01506445 & .02436631 & 0.618 \\
Number of bird & .00019951 & .00010006 & $1.994^{*}$ \\
Credit & .30399168 & .17725424 & $1.715^{*}$ \\
Extension contact & .61078529 & .27974981 & $2.183^{* *}$ \\
Cooperative member & .25369103 & .29086863 & 0.872 \\
Training & .63308414 & .30399318 & $-2.083^{* *}$ \\
\hline MC Fadden Pseudo R-square & 0.385206 & $* *=$ Significant at 5\% \\
Chi square & 6.661641 & $*=$ Significant at $10 \%$ \\
Log likelihood function & -83.13774 & &
\end{tabular}

The regression model result indicated that the poultry farmers' characteristics that significantly influence adoption of biosecurity principle were extension contact, number of birds, credit and training.

Extension contact had a positive and significant influence on adoption of biosecurity principles. Extension is a mean of educating farmers, more educated farmers may be more able to understand the biosecurity concept and see the potential impotence of implementing this management changes. This is in agreement with the findings of Van (2011), who pointed out that frequent contact with extension agents makes farmers have more control over their decision making and make them more confidence to make improved managerial decisions.

Number of birds had a positive significant influence on the adoption of biosecurity principles, the more number of birds a farmer have, the more conscious he becomes to guide against any disease outbreak which could result into a total lost, implying that the more number of birds the more the likelihood of the farmer to adopt bioscurity principles. This is in line with the findings of Onwubuya (2009), who stressed that the higher the number of bird, the higher the adoption of biosecurity principles

Access to credit has positive and significant influence on the adoption of biosecurity principles by the poultry farmers, this is because credit beneficiaries need to avoid the potential large losses caused by disease outbreak. They are prepared to invest more money and times to minimize risk of loss and to ensure higher profit to enable them meet up with their credit obligation.

Accessing to training was significant but had negative effect on adoption of biosecurity principles. The higher the training received by the poultry farmers, the lower the rate of adoption of biosecurity principles. This is because the more the farmers become more skilful through training the more effective and efficient they become in carrying out their managerial activities. This can be achieved by adhering strictly to bioexclusion or external biosecurity, that is, policies developed to prevent the introduction of new pathogen to livestock premises. 
The result indicates that $\mathrm{R}^{2}$ value of regression model was 0.385206 which shows that the economic variables included in the model accounted for $39 \%$ variation in the level of poultry farmer's adoption of biosecurity principles in the study area.

Table 4: Distribution of the respondents based on their perception about the effectiveness of various biosecurity principles

\begin{tabular}{llll}
\hline Perception & & & \\
\hline Biosecurity Principles & $\begin{array}{l}\text { Weighted } \\
\text { score }\end{array}$ & $\begin{array}{l}\text { Weighted } \\
\text { Mean }\end{array}$ & Remark \\
\hline Sanitation & 341 & 3.71 & $* *$ \\
Vaccination & 342 & 3.72 & $* *$ \\
Heating & 303 & 3.29 & $* *$ \\
Cooling & 284 & 3.09 & $* *$ \\
Ventilation & 301 & 3.27 & $* *$ \\
Proper medication & 324 & 3.52 & $* *$ \\
Isolation & 283 & 3.08 & $* *$ \\
Traffic control & 271 & 2.95 & $* *$ \\
Control of rodents & 293 & 3.19 & $* *$ \\
Removal of dead birds & 323 & 3.51 & $* *$ \\
Offering good quality feeds & & & \\
& 353 & 3.84 & $* *$ \\
Critical mean & & 37.17 & $* *$ \\
& $\geq 2.5=* *$ & & \\
\hline
\end{tabular}

Table 4 indicated that respondents perceived sanitation, vaccination, proper medication, removal of dead birds, offering of good quality feeds and offering of good quality water as effective biosecurity principles. . This is in agreement with the findings of Cargill, (1999) and Corbanie, (2007), that Accuracy of vaccine and drug administration and hygienic measures are very important to reduce local reactions, spread of infections, and the iatrogenic induction of disease.

Table 5 revealed that poultry farmers agreed that biosecurity principles are easy to practice (2.54), material affordable (2.85) and accessible (2.67). They however, disagreed that biosecurity materials are cheap (1.85) and does not require special training (1.98). 
Table 5: Distribution of the respondents based on their overall perception on practice of various biosecurity principles

\begin{tabular}{llll}
\hline Perception & Sum & Mean & Remark \\
\hline Easy to practice & 234 & 2.54 & $* *$ \\
Is it affordable & 262 & 2.85 & $* *$ \\
Materials accessible & 246 & 2.67 & $* *$ \\
Materials are cheap to obtain & 170 & 1.85 & $*$ \\
$\begin{array}{l}\text { Does not require special } \\
\text { training }\end{array}$ & & & \\
Critical meam & 182 & 1.98 & $*$ \\
& & 11.87 & $* *$ \\
& & & \\
& $\geq 2.5=* *$ & & \\
& $<2,5=*$ & & \\
\hline
\end{tabular}

Critical mean $=2.5$,

**Agree

*Disagree

Table 6: Perception of respondents about the severity of biosecurity constraints

\begin{tabular}{llllllll} 
Constraints & Very severe & Severe & Undecided & Not severe & Sum & Mean & Remark \\
\hline Inadequate capital & $34(37.0)$ & $39(42.4)$ & - & $19(20.7)$ & 272 & 2.96 & Severe \\
Poor water supply & $5(5.4)$ & $35(38.0)$ & - & $52(56.5)$ & 177 & 1.92 & Not severe \\
High cost of feeds & $13(14.1)$ & $40(43.5)$ & - & $39(42.4)$ & 211 & 2.29 & Severe \\
Marketing problem & $4(4.3)$ & $41(44.6)$ & - & $47(51.1)$ & 186 & 2.02 & Severe \\
Diseases and parasites & $32(34.78)$ & $40(43.48)$ & $5(5.44)$ & $15(16.30)$ & 273 & 2.97 & Severe \\
Lour supply & $4(4.3)$ & $26(28.3)$ & $2(2.2)$ & $60(65.2)$ & 158 & 1.72 & No severe \\
Inadequate credit facilities & $27(29.3)$ & $39(42.4)$ & $1(1.1)$ & $25(27.2)$ & 252 & 2.74 & Severe \\
Poor weather condition & $7(7.6)$ & $31(33.7)$ & $3(3.3)$ & $51(55.4)$ & 178 & 1.93 & No severe \\
Poor veterinary knowledge & $8(8.7)$ & $46(50.0)$ & $4(4.3)$ & $34(37.0)$ & 212 & 2.30 & Severe \\
Pilfering and theft & $5(5.4)$ & $18(19.6)$ & $6(6.5)$ & $63(68.5)$ & 149 & 1.62 & No severe \\
Cultural belief & $1(1.1)$ & $15(16.3)$ & $14(15.2)$ & $62(67.4)$ & 139 & 1.51 & No severe \\
\hline
\end{tabular}

Table 6 indicated that inadequate capital, lack of credit facilities and problem of prevention and control of pathogenic diseases and parasites were more severe than other constraints faced by respondents in the study area, which directly or indirectly affect their adoption of biosecurity principles. This is collaborated by the findings of Siekkinen (2012), who posited that finance is major constraint facing small holder poultry farmers and that of Cristalli and Capua (2007), who pointed out that prevention and control of pathogenic diseases was the major problem facing smallholder poultry farmers in Vietnam.

\section{Conclusions}

This study has shown that majority of the poultry farmers in the study area were still in their active and productive age and a good number of them had one form of education or the other.

Majority of the poultry farmers in the study area are small to medium scale farmers, were aware of the various biosecurity principles and had tried and Adopted a number of them. 
Using the number of the biosecurity principles adopted as the dependent variable, this study identified the potential factors that influence the adoption of biosecurity principles. The regression analysis identified that farmers with larger number of birds, access to credit facilities, and contact with extension agents are more likely to adopt better biosecurity principles.

The farmers perceived biosecurity principles as effective means of preventing diseases, thereby avoiding colossal looses associated with poultry farming.

The study had indicated that poultry farmers in the study area faced serious constraints, but the major and severed constraints faced by them were inadequate capital and poor access to credit.

\section{Recommendations}

i. If biosecurity on small to medium farms are to be encouraged, the unique socioeconomic characteristics of the farmers and the institutional variables of the farms should be considered during the process of encouraging the improvement of the farmer's adoption of biosecurity principles.

ii. Government and NGOs need to understand the drivers of adoption for them to appropriately formulate policies and facilitate decisions that will encourage and motivate smallholder in adopting biosecurity principles in their farms.

iii. Poultry farmers should be adequately train on how to identify the sources/reservoirs and vectors of potential disease agent, for this are the most important step when implementing a biosecurity programme.

\section{References}

Badubi, S.S., Ravindran, V.S. and Reid, J. (2004). A survey of small-scale broiler production systems in Botswana. Tropical Animal Health Production, 36(8): 823-834.

Cargill, P.W. (1999). Vaccine administration in poultry In Practice. Research on Humanities and Social Sciences 21: 323-328 www.iiste.org ISSN 22250484(Online) 2(6).

Corbanie, E. ((2007). Development of a dry powder vaccine for mass vaccination. An unpublished $\mathrm{PhD}$ thesis, faculty of Pharmaceutical sciences, Ghent University.

Cristalli, A. and Capua, I. (2007). Practical problems in controlling H5N1 high pathogenicity avian influenza at village level in Vietnam and introduction of biosecurity measures. Avian Dis., 51(1 Suppl): 461-462

FAO (2008). Biosecurity for highly pathogenic AvianInfluenza. Issues and options. FAO Animal Production and Health Paper 165. Rome, Italy.

Available at http://www.fao.org/ag/ againfo/home/ events/bangkok2007/docs/part2/2_1 .pdf

FAO (2009). Food and Agriculture Organization (2009). FAOSTAT, Production Statistics.

FAO (2012). Faostat. Production. Live animals.

http://faostat.fao.org/site/573/defa $\underline{\text { ult.aspx\#ancor }}$ 
Fasina, F., Alin, A., Yilma, J., Thieme, O. and Ankers, P. (2011). The cost benefit of biosecurity measures on infectious disease in the Eagytian household poultry. Perspective Veterinay Medicine, 103(1-2): 178191

Musa, S.A., Tafida, I. and Gloria, J. (2009). Assessment of Women participation in production of amranthus and Okara in Jos North Local Government Area of Plateau State, Nigeria. . In the Proceedings of 2009 National Conference of Agricultural Extension Society of Nigeria (AESON), held at Federal University of Technology, Minna Between April $21^{\text {st }}$ and $24^{\text {th }} 2009$. Pp80 - 88. Edited by; M.C, Madukwe; T.A. Olowa; E.M. Igbokwe; C.J.C.J. Garford and M.A. Dube.

Nyaga, P. (2007). Good biosecurity practices in small scale commercial and scavenging production systems in Kenya. Rome: FAO.

Nyaga P. (2009). Poultry Sector Analysis: Biosecurity Review and Improved poultry husbandry systems for sectors 3 and 4 to prevent HPAI infection in Uganda. Rome: FAO; 2009.

Nyaga, P.N. (2007a). Avian influenza rapid appraisal and pro-poor livelihoods Consultation on lessons learned. Kenya country report. International Livestock Research Institute (ILRI).

Onwubuya, E.A., Chah, J.M., Nenna, M.G. and Enibe, D.O. (2009). Characteristics of urban agriculture in Enugu Metropolis, Enugu State, Nigeria. . In the Proceedings of 2009 National Conference of Agricultural Extension Society of Nigeria (AESON), held at Federal University of Technology, Minna Between April $21^{\text {st }}$ and $24^{\text {th }}$ 2009. Pp 89 - 101. Edited by; M.C, Madukwe; T.A. Olowa; E.M. Igbokwe, C.J.C.J. Garford and M.A. Dube

Patrick, I. and Jubb, T. (2010). Comparing levels of biosecurity in smallholder broiler and layer farms in Bali and West Jaya. Towards the Adoption of cost-effective biosecurity in NICPOS farms in Indonesia.

Siekkinen, K., Heikkila, J., Tammiranta, N. and Rosengren, H. (2012). Measuring the cost of biosecurity on poultry farms: A case study on the broiler production in Finland. Acta Veterinaria Scandinavica, 54(12): 